\title{
Race, gender, and lifestyle discussions in geriatric primary care medical visits
}

\author{
B. Mitchell Peck ${ }^{1 *}$, Margo-Lea Hurwicz ${ }^{2}$, Marcia Ory ${ }^{3}$, Paula Yuma ${ }^{4}$, Mary Ann Cook ${ }^{5}$ \\ ${ }^{1}$ Department of Sociology, University of Oklahoma, Norman, USA; *Corresponding Author: bmpeck@ou.edu \\ ${ }^{2}$ Department of Anthropology, University of Missouri-St. Louis, St. Louis, USA; hurwicz@umsl.edu \\ ${ }^{3}$ Department of Social and Behavioral Health, School of Rural Public Health, Texas A\&M University System Health Science Center, \\ College Station, USA; mory@srph.tamhsc.edu \\ ${ }^{4}$ Trauma Services, Dell Children's Medical Center of Central Texas, Austin, USA; pyuma@seton.org \\ ${ }^{5}$ JVC Radiology and Medical Analysis, Clayton, USA; JVCRadiology@sbcglobal.net
}

Received 12 August 2010; revised 18 August 2010; accepted 24 August 2010.

\section{ABSTRACT}

Increasingly, healthcare providers are required to spend more time and effort aimed at prevention and lifestyle modification. Many argue that providers are in a unique position to provide information for effective lifestyle and behavior change. Yet, relatively little is known about how interpersonal provider and patient characteristics, such as race and gender, affect discussions of lifestyle choices about public health issues. To understand better how patient and physician characteristics influence discussions of lifestyle behaviors, we conducted a prospective, cohort study of interactions between primary care physicians and their geriatric patients. We videotaped 381 elderly patient visits with 35 primary care physicians. We coded the encounters to indicate whether the patient and physician discussed lifestyle issues around nutrition, physical activity, and smoking. The independent variables were patient and physician race, gender, and concordant status. Discussions about nutrition were the most common lifestyle topic $(47.8 \%)$, followed by physical activity $(40.3 \%)$ and smoking (14.2\%). Multivariate analysis indicate white patients are significantly less likely to have discussions with their physicians about nutrition (OR $=0.32, p=0.02$ ) and same gender encounters are also less likely to discuss diet/nutrition (OR $=0.59, p=0.04)$. There were no significant differences for discussions about physical activity

\footnotetext{
*This manuscript was based on work supported by the Texas A \& M University System School of Rural Public Health, Scott and White Health Plan Health Services Research Program, and NIA SBIR Contract Number N43-AG-6-2118 and Grant Number R44AG15737.
}

or smoking. Previous research has shown that differences persist in the quality of care and certain outcomes. Our results suggest these differrences are not exclusively the result of differences in the prevalence of lifestyle discussions based on patient and physician race or gender.

Keywords: Doctor-Patient Relations; Geriatrics; Race; Gender

\section{INTRODUCTION}

The primary causes of mortality in the United States and other industrialized nations have shifted from acute illnesses to chronic conditions. The three leading causes of mortality in the United States in 2006 were heart disease, cancer, and stroke [1]. These deaths are attributed to tobacco use, poor diet, and physical inactivity [2]. Health care delivery continues to change as a result of these trends in mortality, and other factors like the aging U.S. population [3]. Increasingly, health care providers spend more time and effort aimed at prevention and lifestyle modification [4]. Many argue that health care providers are in a unique position to provide information and advice for effective lifestyle and behavior change [5,6]. Recent research suggests that physicians and other health care providers are important and effective facilitators for change of health-related behaviors $[7,8]$. Relatively little research, however, has been directed toward understanding the role of interpersonal provider and patient characteristics, such as race and gender, on discussions of lifestyle choices about specific public health issues. This study aims to answer two questions. First, what is the prevalence of discussions about nutrition, physical activity, and smoking in geriatric primary care medical visits? Second, does the prevalence of lifestyle discussions 
about nutrition, exercise, and smoking vary by patient and/or physician race and gender? We focus on geriatric patients because they represent an important and growing segment of American society [3]. They are also less likely than other groups to engage in regular physical activity, and more vulnerable to the consequences of unhealthy behaviors and poor nutrition [9].

\section{MATERIALS AND METHODS}

\subsection{Research Setting and Subjects}

We videotaped 423 patient visits to 36 general medicine/ family medicine physicians at three separate health care sites over a two-year period beginning August 1998. Patients were recruited in the waiting room of physician offices before their visit to the doctor. To be eligible for the study, patients had to be at least 65 years of age and identify the physician as their usual source of care. Physicians were recruited from all practicing physicians at the study sites.

Before the visit, patients completed a pre-visit questionnaire that included sociodemographic information and the reason for that day's medical visit. We videotaped all consented patients' medical visit. Immediately after the visit, patients completed a post-visit questionnaire that included the SF-36 Health Status Questionnaire and satisfaction with the visit. Participating physicians completed a brief demographic survey that assessed age, gender, race, years of practice, specialty, and history of any geriatric training, including specialization, medical school coursework, and continuing education activities.

Patients, companions accompanying the patient into the exam room, and physicians provided written informed consent before participation in the study. The physician-patient pairs used for the study were restricted to encounters in which patients had seen the physician at least on one prior occasion. Physicians were aware of the research project, but blinded to the hypotheses.

\subsection{Measures}

We examined three separate dependent variables: 1) physician discussion of nutrition or diet; 2) discussion of exercise or physical activity; and 3) discussion of tobacco smoking. Trained coders observed videotapes of the medical encounters. Each coder received, on average, 40 hours of training for identifying and rating communication behaviors and documenting discussion of items in the medical encounter. The coders noted the occurrence of a topic if the physician made any mention of the above named topics in any context. The variables are dichotomous, indicating the presence or absence of discussion of a topic at any time during the medical encounter.

\subsection{Independent Variables}

We collected patient demographic variables including age, gender, race, education, and perception of income adequacy (not enough, enough, comfortable). Because we were interested in the racial concordance/discordance and our sample included so few patients of races and ethnicities other than Whites and African-Americans, we excluded Hispanics, Asians, and all other non-White and non-African-American patients from the analyses. Education was coded as a binary variable indicating at least some college education versus all others. Perception of income adequacy was coded as a binary variable indicating having a comfortable income level versus all others. In addition to the demographic information, we assessed the patients' physical functioning using a subscale from the SF-36 Health Status Questionnaire [10].

Physician variables include age, gender, race, specia1ty, history of geriatric training (including specialization, medical school coursework, and continuing education activities), and years of practice. As with the patients, we excluded all non-White and non-African-Ameri-can physicians from the analyses.

Medical encounter or contextual variables included the patients' reason for the medical visit, the length of the visit, and length of the relationship between doctor and patient. Reason for the visit was coded as non-acute versus acute, based on the patients' statement of the reason(s) for visiting the physician that day. Patients often cited multiple reasons for that day's visit. The visit was coded as "acute" if any of the reasons were identified as acute medical concerns. Length of the medical visit was recorded in seconds and converted to minutes. Length of the doctor-patient relationship was coded in years. Two scales from the ADEPT Scale (Assessment of Doctor-Elderly Patient Encounters) were used to assess the quality of the encounters [11]. Physicians receive higher supportiveness scores for visual attentiveness, eliciting and acknowledging patient verbal and nonverbal communications, and making empathetic statements. Informing scores are affected by offering solutions, giving explanations for instructions, and soliciting patients' input for treatment plans.

\subsection{Data Analysis}

The primary dependent variables are binary: lifestyle discussions (yes/no) of nutrition, physical activity, and smoking. We, therefore, present odds ratios from binary logistic regression analyses. Because the data are clustered - patients clustered by physicians - the individual observations are not independent, potentially affecting estimates of the standard errors. We conducted all analyses using the Huber-White sandwich correction for nonindependent observations $[12,13]$. 
We present both unadjusted and adjusted multivariate models. In the multivariate models, we adjusted for patients' age, education, insurance status, income, physical functioning (SF-36), vitality (SF-36), physicians' age, years of practice, geriatric training, and length of visit, reason for visit (acute), length of doctor-patient relationship, presence of a patient companion, ADEPT supportiveness and informativeness. For the categorical independent variables, we express the results in terms of odds ratios based on referent categories. The continuous independent variables results are presented in terms of unit changes. We used Stata version 11 to perform all analyses (Stata Corp, College Station, TX).

\section{RESULTS}

\subsection{Sample Characteristics}

As shown in Table 1, the patient population was primar- ily female (66.4\%), white (84.3\%), fairly well educated (three-quarters of the sample had at least a high school education), with sufficient financial means (only $15.8 \%$ reported their income was not enough to meet their needs). More than half the patients were younger than 73 years of age (median age 74 ), while $10 \%$ were 85 years or older. The physical functioning score (median score 65 ) reflects the elderly study sample and is considerably below the national average of 84.2 for all adults.

The physicians were mostly male $(77.1 \%)$ and white (83.9\%). Most were under the age of 50 (median age 48). Slightly more than a quarter reported having some geriatric training, either via specialization, medical school coursework, or continuing education activities. The physicians average 23 years of practice experience.

Most patients presented for non-acute reasons (78.4\%). The visits ranged in length from 4.5 to over 47 minutes (median time 15.1 minutes). These were continuing patient

Table 1. Characteristics of the patient and physician subjects. ${ }^{\dagger}$

\begin{tabular}{|c|c|c|c|c|c|}
\hline Patient Characteristics & $\begin{array}{c}\text { Total } \\
(\mathrm{n}=\mathbf{3 8 1})\end{array}$ & $\begin{array}{c}\text { White } \\
(n=321)\end{array}$ & $\begin{array}{l}\text { African-American } \\
(n=60)\end{array}$ & $\begin{array}{c}\text { Male } \\
(n=128)\end{array}$ & $\begin{array}{c}\text { Female } \\
(n=253)\end{array}$ \\
\hline Age, median & 74.0 & 74.0 & 72.0 & 74.0 & 74.0 \\
\hline Gender Female & 66.4 & 65.1 & 73.3 & - & - \\
\hline Education More than HS & 45.7 & 48.9 & 29.3 & 54.7 & 41.1 \\
\hline Private Insurance & 18.8 & 18.2 & 22.0 & 20.6 & 17.9 \\
\hline Comfortable Income & 44.5 & 49.5 & 18.6 & 54.3 & 39.3 \\
\hline SF-36 Physical Function, median & 65.0 & 65.0 & 65.0 & 80.0 & 55.2 \\
\hline SF-36 Vitality, median & 55.0 & 55.0 & 57.5 & 55.0 & 55.0 \\
\hline \multicolumn{6}{|l|}{ Gender of Physician Seen } \\
\hline Male & 75.1 & 77.6 & 61.7 & 85.9 & 69.6 \\
\hline Female & 24.9 & 22.4 & 38.3 & 14.1 & 30.4 \\
\hline \multicolumn{6}{|l|}{ Race of Physician Seen } \\
\hline White & 83.7 & 97.2 & 11.7 & 87.5 & 81.8 \\
\hline African-American & 16.3 & 2.8 & 88.3 & 12.5 & 18.2 \\
\hline Length of Visit (Minutes), median & 15.1 & 16.1 & 13.1 & 14.4 & 15.8 \\
\hline Years with Physician, median & 3.0 & 3.0 & 8.0 & 5.0 & 3.0 \\
\hline Physician Characteristics & $\begin{array}{c}\text { Total } \\
(n=35)\end{array}$ & $\begin{array}{c}\text { White } \\
(n=29)\end{array}$ & $\begin{array}{c}\text { African-American } \\
(n=6)\end{array}$ & $\begin{array}{c}\text { Male } \\
(n=27)\end{array}$ & $\begin{array}{c}\text { Female } \\
(n=8)\end{array}$ \\
\hline Age, median & 48.0 & 44.0 & 57.0 & 47.0 & 49.5 \\
\hline Gender Female & 22.9 & 17.2 & 50.0 & - & - \\
\hline Race African-American & 17.1 & - & - & 11.1 & 37.5 \\
\hline Years of Practice, median & 23.0 & 22.0 & 25.0 & 23.0 & 18.5 \\
\hline Geriatric Training & 25.7 & 20.7 & 50.0 & 18.5 & 50.0 \\
\hline Encounter Characteristics & $\begin{array}{c}\text { Total } \\
(n=381)\end{array}$ & $\begin{array}{c}\text { White } \\
(n=321)\end{array}$ & $\begin{array}{l}\text { African-American } \\
(n=60)\end{array}$ & $\begin{array}{c}\text { Male } \\
(n=128)\end{array}$ & $\begin{array}{c}\text { Female } \\
(n=253)\end{array}$ \\
\hline Length of Visit (minutes), median & 15.1 & 16.1 & 13.1 & 14.4 & 15.8 \\
\hline Non-acute Reason for Visit & 78.4 & 77.2 & 85.0 & 82.0 & 76.6 \\
\hline Years with Physician, median & 3.0 & 3.0 & 8.0 & 5.0 & 3.0 \\
\hline Presence of Companion & 16.8 & 19.3 & 3.3 & 13.3 & 18.6 \\
\hline \multicolumn{6}{|l|}{ Rating of Physician Supportiveness } \\
\hline \multicolumn{6}{|l|}{ Rating of Physician Informativeness } \\
\hline Low & 31.5 & 28.3 & 49.1 & 35.4 & 29.4 \\
\hline Medium & 38.1 & 38.7 & 35.1 & 41.7 & 36.3 \\
\hline High & 30.4 & 33.0 & 15.8 & 22.8 & 34.3 \\
\hline
\end{tabular}

'Data are percentages except where noted. 
visits with an average length of doctor-patient relationship of three years. However, almost a third of the patients $(32 \%)$ had been seeing the doctor less than a year and nearly a fifth (18.4\%) had been seeing the same doctor for 10 years or more. Table 1 also presents the sample characteristics by patient race and gender.

\subsection{Prevalence of Lifestyle Discussions}

Descriptive analyses of the full sample revealed no single lifestyle topic mentioned in more than half of the encounters (Table 2). Discussions about nutrition were the most common lifestyle topic. Almost half (47.8\%) of the visits included a discussion about diet/nutrition, followed by exercise or physical activity $(40.3 \%)$ and smoking (14.2\%).

Bivariate analyses showed there were few differences in discussions based on patient or physician gender and race. Discussions about nutrition occurred more often with African-American patients (66.7\% versus $44.4 \%, p$ $=0.002)$. Nutrition discussions were more prevalent in encounters with African-American physicians compared to their white counterparts $(61.3 \%$ versus $45.3 \%$, respectively). There were no bivariate differences in discussions about physical activity based on race, gender, or concordance status. The only significant difference in discu-

Table 2. Percent of medical encounters with lifestyle discussions by patient and physician gender and race $(P$ value $) \dagger$.

\begin{tabular}{|c|c|c|c|}
\hline Characteristic & $\begin{array}{c}\text { Nutrition } \\
47.8 \%\end{array}$ & $\begin{array}{c}\text { Physical Activity } \\
40.3 \%\end{array}$ & $\begin{array}{c}\text { Smoking } \\
14.2 \%\end{array}$ \\
\hline \multicolumn{4}{|l|}{ Patient Gender } \\
\hline Male & 43.8 & 46.1 & 16.4 \\
\hline \multirow[t]{2}{*}{ Female } & 50.0 & 37.3 & 13.1 \\
\hline & $(.27)$ & $(.12)$ & $(.43)$ \\
\hline \multicolumn{4}{|l|}{ Patient Race } \\
\hline White & 44.4 & 42.2 & 14.7 \\
\hline \multirow[t]{2}{*}{ African-American } & 66.7 & 30.0 & 11.7 \\
\hline & $(0.00)$ & $(0.08)$ & $(0.68)$ \\
\hline \multicolumn{4}{|l|}{ Physician Gender } \\
\hline Male & 46.7 & 41.8 & 12.9 \\
\hline \multirow[t]{2}{*}{ Female } & 51.6 & 35.8 & 17.9 \\
\hline & $(0.41)$ & $(0.33)$ & $(0.23)$ \\
\hline \multicolumn{4}{|l|}{ Physician Race } \\
\hline White & 45.3 & 42.1 & 15.1 \\
\hline \multirow[t]{2}{*}{ African-American } & 61.3 & 30.7 & 9.7 \\
\hline & $(0.02)$ & $(0.11)$ & $(0.32)$ \\
\hline \multicolumn{4}{|l|}{ Gender Concordance } \\
\hline No & 52.2 & 37.3 & 11.4 \\
\hline \multirow[t]{2}{*}{ Yes } & 43.3 & 43.3 & 17.1 \\
\hline & $(0.08)$ & $(0.25)$ & $(0.14)$ \\
\hline \multicolumn{4}{|l|}{ Race Concordance } \\
\hline No & 62.5 & 43.8 & 43.8 \\
\hline \multirow[t]{2}{*}{ Yes } & 47.3 & 40.1 & 12.9 \\
\hline & $(0.30)$ & $(0.79)$ & $(0.00)$ \\
\hline \multicolumn{4}{|c|}{ Gender \& Race Concordance } \\
\hline No & 52.2 & 37.4 & 12.8 \\
\hline \multirow[t]{2}{*}{ Yes } & 42.9 & 43.5 & 15.8 \\
\hline & $(0.08)$ & $(0.24)$ & $(0.46)$ \\
\hline
\end{tabular}

†Standard errors are corrected using Huber-White sandwich matrix estimator that does not assume independence of cases within clusters. ssions about smoking was between racially concordant and discordant encounters. Almost half (43.8\%) of the encounters in which the patient and physician were of a different race discussed smoking, compared to only $12.9 \%$ of the racially concordant encounters.

\subsection{Gender, Race, and Concordance on Lifestyle Discussions}

Table 3 presents the analyses examining the relationships between gender, race, and concordant status on lifestyle discussions. Unadjusted (bivariate) and adjusted (multivariate) results are presented. Like the bivariate relationships presented above, most of the significant associations in the unadjusted models involve the race variables. Of the 13 significant associations in the unadjusted models, only 3 involve gender variables. After adjusting for the patient, physician, and encounter/contextual variables, few relationships remained statistically significant. The adjusted models show that the only significant differences are in discussions about diet/nutrition. White patients are significantly less likely to have discussions with their physicians about nutrition $(\mathrm{OR}=0.32$, $p=0.02)$. Encounters with same gender patients and physicians are also less likely to discuss diet or nutrition $(\mathrm{OR}=0.59, p=0.04)$.

\section{DISCUSSION}

Given the increasing importance of prevention and lifestyle modification in the clinical encounter, especially for aging and other vulnerable populations, it is important to understand the factors that contribute or inhibit discussion of lifestyle and health-related behaviors. Our study found that fewer than half of physicians even discussed nutrition, physical activity, or smoking issues with their elderly patients. Most of the differences in the prevalence of discussions were the result of the racial composition of the patient and physician. Fewer differences based on gender existed. Few of the racial differentces, however, persisted after adjusting for potential confounders.

Previous studies, in general, have found racial and/or gender differences in various aspects of the clinical encounter. For example, medical visits with female physicians are, on average, longer than those of male physicians and typically engage in more communication that can be considered patient-centered [14]. Likewise, racial differences in health outcomes [15], quality of care [16], and style of communication [17] have been observed. Our study did not provide as clear or consistent findings as these previous findings.

That our study did not produce findings consistent with previous research is likely due to one of several factors. 
Table 3. Relationship of patient and physician race, gender, and concordance to lifestyle discussions. ${ }^{\dagger}$

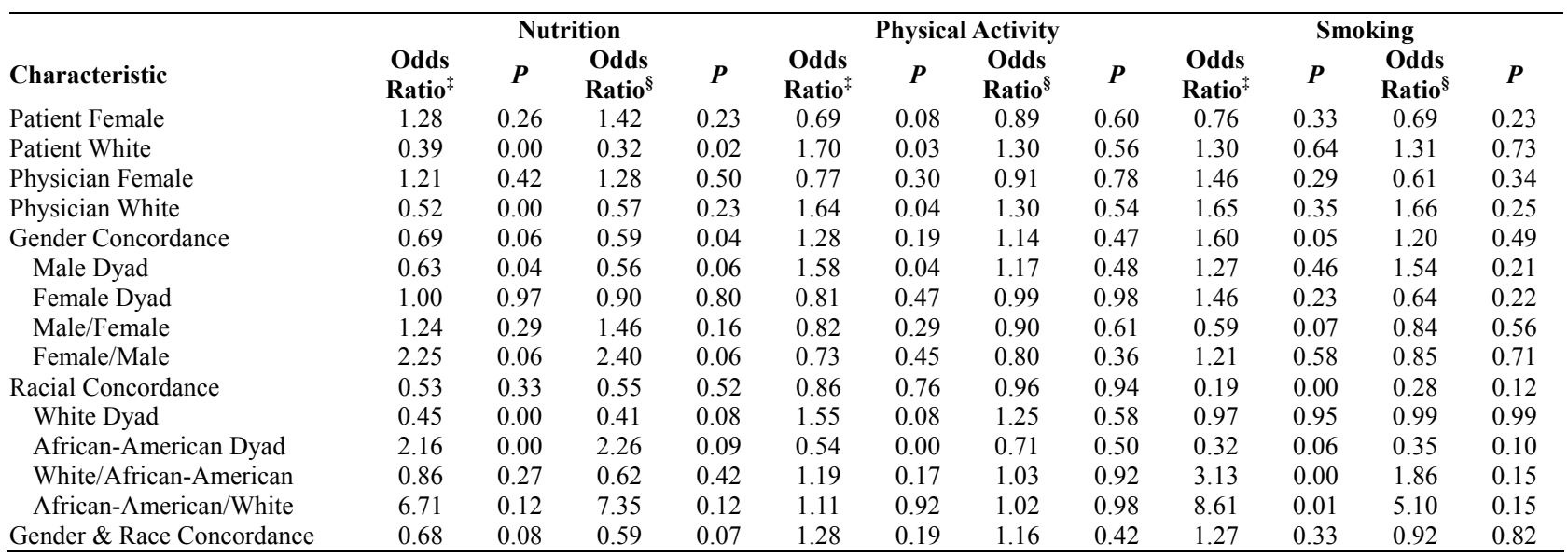

${ }^{\dagger}$ Standard errors are corrected using Huber-White sandwich matrix estimator that does not assume independence of cases within clusters; ${ }^{\dagger}$ Unadjusted odds ratios; ${ }^{\S}$ Adjusted for patients' age, education, insurance status, income, physical functioning (SF-36), vitality (SF-36), physicians' age, years of practice, geriatric training, and length of visit, reason for visit (acute), length of doctor-patient relationship, presence of a patient companion, ADEPT supportiveness, ADEPT informativeness.

First, our outcome is different from many previous studies. Our study examined neither actual outcomes (such as readmissions, satisfaction health status) nor the style or process of communication in the encounter (empathy, patient-centered, participatory decision making). Rather, we examined the content of the encounter, whether or not the patient and physician discussed lifestyle behaviors. Another possible explanation for the difference in findings is the patient population. There is a substantial body of literature examining race and gender differences in the clinical encounter, as well as studies that examine differences in adult and elderly patient populations. There have been many fewer studies that account for both differences. Finally, our finding may differ from previous results because of limitations of our study. Most importantly, the study was observational in nature, with no randomization of patients to physicians. It is reasonable, that patients self-select to a physician of a particular race or gender. A further limitation is the size of the sample. There are significantly fewer African-American and female physicians than white and male physicians.

Despite these limitations, this study provides a better understanding of the prevalence of discussions about lifestyle and health-related behaviors in geriatric medical visits and potential sources of variation in those discussions. Our study suggests that physicians discuss nutrition, physical activity and smoking behavior in fewer than half of all geriatric visits. There are relatively few differences in the prevalence of these discussions based on race and gender of the patient or physician.

\section{REFERENCES}

[1] Heron, M. (2010) Deaths: Leading causes for 2006. $\mathrm{Na}$ - tional Vital Statistics Reports, 58, National Center for Vital Statistics, Hyattsville.

[2] Mokdad, A.H., et al. (2004) Actual causes of death in the United States, 2000. Journal of the American Medical Association, 291(10), 1238-1245.

[3] Day, J.C. (2006) Projections of the number of housholds and families in the United States: 1995 to 2010, U.S. Bureau of the Census, Current Population Reports, P25-1129. U.S. Government Printing Office, Washington, DC.

[4] Beaudoin, C., et al. (2001) Discussion of lifestyle-related issues in family practice during visits with general medical examination as the main reason for encounter: an exploratory study of content and determinants. Patient Education and Counseling, 45(4), 275-284.

[5] Nutting, P.A. (1986) Health promotion in primary medical care: Problems and potential. Preventive Medicine, 15(5), 537-548.

[6] Stott, N.C. (1986) The role of health promotion in primary health care. Health Promotion, 1(1), 49-53.

[7] Glasgow, R.E., et al. (2001) Physician advice and support for physical activity: Results from a national survey. American Journal of Preventive Medicine, 21(3), 189196.

[8] Wiggers, J.H. and Sanson-Fisher, R. (1994) General practitioners as agents of health risk behavior change: Opportunities for behavioral science in patient smoking cessation. Behaviour Change, 11(2), 167-176.

[9] Institute of Medicine (1999) The role of nutrition in maintaining health in the nation's elderly: Evaluating coverage of nutrition services for the medicare population. National Academy Press, Washington, DC.

[10] Ware Jr., J.E. and Sherbourne, C.D. (1992) The MOS 36-item short-form health survey (SF-36). I. Conceptual framework and item selection. Medical Care, 30(6), 473-483.

[11] Cook, M.A. (2002) Final report: Assessment of doctor-elderly patient encounters. National Institute on Aging, Washington, DC. 
[12] Huber, P.J. (1967) The behavior of maximum likelihood estimates under nonstandard conditions. Proceedings of the 5th Berkeley Symposium on Mathematical Statistics and Probability: Statistics, 1(1), 221-233.

[13] White, H. (1980) A heteroskedasticity-consistent covariance matrix estimator and a direct test for heteroskedasticity. Econometrica, 48(4), 817-830.

[14] Roter, D.L. and Hall, J.A. (2004) Physician gender and patient-centered communication: a critical review of empirical research. Annual Review of Public Health, 25(1), 497-519.
[15] Epstein, A.M., et al. (2003) Race and gender disparities in rates of cardiac revascularization: do they reflect appropriate use of procedures or problems in quality of care? Medical Care, 41(11), 1240-1255.

[16] Institute of Medicine (2002) Unequal treatment: confronting racial and ethnic disparities in health care. National Academy Press, Washington, DC.

[17] Cooper-Patrick, L., et al. (1999) Race, gender, and partnership in the patient-physician relationship. Journal of the American Medical Association, 282(6), 583-589. 